\title{
A Distance Measure of Interval-valued Belief Structures
}

(Suatu Jarak Pengukuran Nilai Selang Struktur Kepercayaan)

\author{
JUNQIN CAO, XUEYING ZHANG* \& JIAPENG FENG
}

\begin{abstract}
Interval-valued belief structures are generalized from belief function theory, in terms of basic belief assignments from crisp to interval numbers. The distance measure has long been an essential tool in belief function theory, such as conflict evidence combinations, clustering analysis, belief function and approximation. Researchers have paid much attention and proposed many kinds of distance measures. However, few works have addressed distance measures of interval-valued belief structures up. In this paper, we propose a method to measure the distance of interval belief functions. The method is based on an interval-valued one-dimensional Hausdorff distance and Jaccard similarity coefficient. We show and prove its properties of non-negativity, non-degeneracy, symmetry and triangle inequality. Numerical examples illustrate the validity of the proposed distance.
\end{abstract}

Keywords: Distance; Hausdorff distance; interval-valued belief structures; Jaccard similarity coefficient

\section{ABSTRAK}

Nilai selang struktur kepercayaan digeneralisasi daripada teori fungsi kepercayaan, dari sudut tugasan kepercayaan asas nombor krisp kepada selang. Jarak pengukuran telah menjadi alat yang penting dalam teori fungsi kepercayaan, seperti gabungan bukti konflik, analisis berkelompok, fungsi kepercayaan dan penganggaran. Penyelidik telah memberi banyak perhatian dan mencadangkan pelbagai jenis jarak pengukuran. Walau bagaimanapun, beberapa kajian telah membincangkan jarak pengukuran nilai selang struktur kepercayaan. Dalam kertas ini, kami mencadangkan kaedah untuk mengukur jarak fungsi selang kepercayaan. Kaedah ini berdasarkan jarak nilai selang satu dimensi Hausdorff dan pekali kesamaan Jaccard. Kami tunjuk dan buktikan sifatnya yang tidak negatif, tidak merosot, simetri dan ketidaksamaan segitiga. Contoh berangka menunjukkan kesahan jarak yang dicadangkan.

Kata kunci: Jarak; jarak Hausdorff; nilai selang struktur kepercayaan; pekali kesamaan Jaccard

\section{INTRODUCTION}

The Dempster-Shafer theory (DST), also called evidence theory or belief function theory, was presented by Dempster (1967), and extended and refined by his student, Glenn Shafer (1976). It has been developed and applied in areas such as fault diagnosis (Wu et al. 2010; Yuan et al. 2016), decision making (Bauer 1997; Giang 2015), pattern classification (Liu et al. 2014; Thierry \& Philippe 2007), and clustering (Hariz et al. 2006). Among the tools developed to work with DST, distances have recently received increased attention and much work on measuring the distance or dissimilarity between two belief functions has emerged (Jousselme \& Maupin 2012). The distance measure can describe the degree of dissimilarity or similarity between bodies of evidence (BOE), and that has been proposed as a tool in various applications including conflict evidence combination (Deng et al. 2004; Martin et al. 2008), clustering analysis (Deneux 2000), learning models (Zouhal 1998) and belief function approximation (Cuzzolin 2011; Klein et al. 2016; Tessem 1993).

However, in practice, incompleteness or lack of information causes partial or total ignorance, and assigning a crisp number to every focal element is often regarded as too restrictive. Interval-valued data arise in situations requiring management of either the uncertainty related to measurements or the variability inherent in a group rather than an individual. In the literature, Denoeux (1999), Lee and Zhu (1992), and Yager (2001) have attempted to extend DST to interval-valued belief structures (IBS). Within the framework of the transferable belief model (TBM), Denoeux extended the main concepts of DST, which include credibility, plausibility, combination and normalization which lay the theoretical foundations of IBS. Most research fields of IBS involve combination rule (Fu \& Yang 2012, 2011; Sevastianov 2012; Song et al. 2014; Wang 2007), normalization (Sevastjanov et al. 2010; Xu et al. 2012), and uncertainty measure (Jiang 2017; Son 2016). However, few are concerned with the distance within the framework of IBS.

Among the referenced papers, the distances of DST can be roughly divided into direct and indirect distances (Loudahi et al. 2016). A type of direct distance, Jousselme's distance (Jousselme et al. 2001) is essentially a weighted Euclidean distance using the Jaccard similarity coefficient to measure the similarity of focal elements. It has proven highly attractive because it satisfies the mathematical 
constraints of a metric distance (non-negativity, nondegeneracy, symmetry and triangle inequality). A variety of other distances have since been proposed using different similarity functions between focal elements (Diaz et al. 2006; Sunberg et al. 2013). Sunberg used Hausdorff-based measure to account for the distance between focal elements which must be orderable sets. Mo et al. (2016) proposed a generalized method to measure the evidence distance which combines Jousselme's distance and Sunberg's distance by tunable parameters. Among indirect distances, the pignistic probability transform turns a belief function into the least committed probability distribution. Tessem's distance (also called the betting commitment distance or the pignistic probability distance) is used to compute approximations of basic belief assignments. Another kind of indirect distance measure is based on belief intervals (Han et al. 2014; Yang \& Han 2015) which transform the evidential distance to the distance of intervals. For a thorough survey of evidential distances and their classification, see Jousselme et al. (2001).

In view of the importance of interval-valued evidential distances, we propose a distance in IBS. We use the Jaccard similarity coefficient to measure the similarity of focal elements and the Hausdorff distance to measure the distance between interval numbers. The proposed interval distance can measure both the crisp and the interval-valued belief structures (Fallatah et al. 2018; Huh et al. 2018; Kaushik \& Chatterjee 2018; Li et al. 2018; Yang et al. 2018).

The rest of this paper is organized as follows. Next, we briefly review the fundamental notions of evidence theory and interval-valued belief structures (Oyekale 2017; Pedroza et al. 2017; Sigren 2018; Skibicki 2017; Wahi et al. 2018). Some evidential distances in DST literature are discussed in subsequent section. A new distance of interval evidence is proposed in the following section. Some desired properties and related proofs about the distance are also provided. Experiments and simulations are described in the last section.

\section{BACKGROUND}

We review some basic concepts commonly used in DST and IBS.

\section{BASICS OF BELIEF FUNCTIONS}

The basic concepts of DST were first introduced by Dempster and developed by Shafer. The following definitions are central in evidence theory.

Definition 1 Let $\Theta=\left\{\theta_{1}, \theta_{2}, \ldots, \theta_{n}\right\}$ be a finite set of mutually exclusive sets of propositions, referred to as a frame of discernment (FOD). A basic belief assignment (BBA) $m$, is defined as a mapping from $2^{\Theta}$ to $1\left(m: 2^{\Theta} \rightarrow\right.$ $[0,1])$, which satisfies,

$$
\sum_{A \subseteq \Theta} m(A)=1, m(\varnothing)=0 .
$$

A set $A$ is a focal element of $m$ iff $m(A)>0$. A BBA is also called a mass function. The set of all focal elements and their corresponding mass assignments constitutes a body of evidence (BOE).

Definition 2 The belief and plausibility commonality functions of a set $A$ are respectively defined as,

$$
\begin{aligned}
& \operatorname{Bel}(A)=\sum_{B \subseteq A} m(B), \\
& \operatorname{Pl}(A)=\sum_{A \cap B \neq \varnothing} m(B) .
\end{aligned}
$$

$\operatorname{Bel}(A)$ represents how much the event $A$ is implied by the actual evidence, i.e. how much the justified specific support exits for focal element $A$. $P l(A)$ represents how consistent the event $A$ is with the actual evidence, i.e. how much the potential specific support exists for $A$. The length of the belief interval $[\operatorname{Bel}(A), P l(A)]$ represents the degree of imprecision for $A$.

Definition 3 The pignistic probability corresponding to a BBA is defined by,

$$
\operatorname{Bet}_{m}(A)=\sum_{B \in 2^{\ominus}} \frac{|A \cap B|}{|B|} m(B) .
$$

Called the betting commitment to $A$. $\operatorname{BetP}_{m}(A)$ provides the total mass value that $A$ can carry.

The core of evidence theory is Dempster's rule of combination by which evidence from different sources is combined.

Definition 4 With two belief structures $m_{1}$ and $m_{2}$, Dempster's rule of combination is defined as,

$$
\left[m_{1} \oplus m_{2}\right](C)=\left\{\begin{array}{lc}
\frac{\sum_{A \cap B=C} m_{1}(A) m_{2}(B)}{1-K} & \forall C \subseteq \Theta, C \neq \varnothing, \\
0 & C=\varnothing
\end{array}\right.
$$

where $\oplus$ represents the combination operator, also called the orthogonal sum; $A$ and $B$ are focal elements; $K=\sum_{A \cap B=\varnothing} m_{1}(A) m_{2}(B)$ is the conflict coefficient, which measures the conflict between the pieces of evidence; and division by $(1-K)$ is called normalization.

\section{BASICS OF INTERVAL-VALUED BELIEF FUNCTIONS}

In an IBS, belief masses are no longer described by precise numbers, but lie within certain intervals. It is constrained as follows (Smets \& Kennes 1994).

Definition 5 Let $\Theta$ be the frame of discernment, $F_{1}, F_{2}, \ldots$, $F_{N}$ be $N$ subsets of $\Theta$ and $\left[a_{i}, b_{i}\right]$ be $N$ intervals with $0 \leq a$ $\leq b_{i} \leq 1(i=1,2, \ldots, N)$. An interval-valued belief structure (IBS) is a belief structure on $\Theta$ such that, 
(1) $a_{i} \leq m\left(F_{i}\right) \leq b_{i}$, where $0 \leq a_{i} \leq b_{i} \leq 1$ for $i=1,2, \ldots, N$;

(2) $\sum_{i=1}^{N} a_{i} \leq 1$ and $\sum_{i=1}^{N} b_{i} \geq 1$;

(3) $m(H)=0, \forall H \notin\left\{F_{1}, F_{2}, \ldots, F_{N}\right\}$.

If an IBS satisfies the above, we can say it is valid.

Definition 6 Let $m$ be a valid IBS such that $a_{i} \leq m\left(F_{i}\right) \leq b_{i}$. If $a_{i}$ and $b_{i}$ satisfy

$$
\sum_{j=1}^{N} b_{j}-\left(b_{i}-a_{i}\right) \geq 1 \text { and } \sum_{j=1}^{N} a_{j}+\left(b_{i}-a_{i}\right) \leq 1, i=1,2, \ldots, N
$$

then $m$ is said to be normalized.

A normalized IBS is valid, but the converse is not always true.

If an IBS is valid, but not normalized, then it can be normalized by (6) and (7).

$$
\begin{aligned}
& \hat{a}_{i}=\frac{a_{i}}{a_{i}+\sum_{j=1, j \neq i}^{N} b_{j}}, i=1,2, \ldots, N \\
& \hat{b}_{i}=\frac{b_{i}}{b_{i}+\sum_{j=1, j \neq i}^{N} a_{j}}, i=1,2, \ldots, N .
\end{aligned}
$$

Any IBSs in this paper is assumed to be valid and normalized.

Definition 7 Let $m_{1}$ and $m_{2}$ be two interval-valued belief structures with interval-valued probability masses $m_{1}^{-}\left(A_{i}\right) \leq m_{1}\left(A_{i}\right) \leq m_{1}^{+}\left(A_{i}\right)$ for $i=1$ to $n_{1}$ and $m_{1}^{-}\left(B_{j}\right) \leq m_{1}\left(B_{j}\right) \leq m_{1}^{+}\left(B_{j}\right)$ for $j=1$ to $n_{2}$, respectively. Their combination, denoted by $m_{1} \oplus m_{2}$, is also an interval-valued belief structure defined by,

$$
\left[m_{1} \oplus m_{2}\right](C)=\left\{\begin{array}{lc}
{\left[\left(m_{1} \oplus m_{2}\right)^{-}(C),\left(m_{1} \oplus m_{2}\right)^{+}(C)\right]} & \forall C \subseteq \Theta, C \neq \varnothing, \\
0 & C=\varnothing
\end{array}\right.
$$

where $\left(m_{1} \oplus m_{2}\right)^{-}(\mathrm{C})$ and $\left(m_{1} \oplus m_{2}\right)^{+}(\mathrm{C})$ are respectively the minimum and maximum of the following pair of optimization problems:

$$
\begin{array}{ll}
\text { Max/Min } & {\left[m_{1} \oplus m_{2}\right](C)=\frac{\sum_{A_{i} \cap B_{j}=C} m_{1}\left(A_{i}\right) m_{2}\left(B_{j}\right)}{1-\sum_{A_{i} \cap B_{j}=\varnothing} m_{1}\left(A_{i}\right) m_{2}\left(B_{j}\right)}} \\
\text { s.t. } & \sum_{i=1}^{n_{1}} m_{1}\left(A_{i}\right)=1 \\
& \sum_{j=1}^{n_{2}} m_{2}\left(B_{j}\right)=1 \\
& m_{1}^{-}\left(A_{i}\right) \leq m_{1}\left(A_{i}\right) \leq m_{1}^{+}\left(A_{i}\right), i=1,2, \ldots, n_{1}, \\
& m_{2}^{-}\left(B_{j}\right) \leq m_{2}\left(B_{j}\right) \leq m_{2}^{+}\left(B_{j}\right), j=1,2, \ldots, n_{2} .
\end{array}
$$

Wang's combination rule is a quadratic optimization with constraint conditions and the combination and normalization of two pieces of interval evidence produces occur at the same time rather than separately.

\section{DISTANCE IN THE THEORY OF BELIEF FUNCTIONS}

A distance or dissimilarity between two BBAs can represent the degree of dissimilarity between BOEs. Much work on measuring the distance has emerged recently, but there is no distance measure for IBSs. The following common distances in DST can be roughly classified as either direct or indirect distances.

In view of the geometric interpretation (Cuzzolin 2008), basic belief assignments can be seen as vectors belonging to the simplex of a vector space $E$, which spanned by the elements of the power set $2^{\Theta}$ and has the dimension $\left|2^{\Theta}\right|$. For two belief functions, the direct distance is defined directly on the space $E \times E$.

Jousselme's distance is a type of direct distance. Let $m_{1}$ and $m_{2}$ be two BBAs defined on the same FOD $\Theta$, containing $n$ mutually exclusive and exhaustive hypotheses. $A$ and $B$ are any focal elements of BBAs $m_{1}$ and $m_{2}$. Jousselme's distance, denoted by $d_{\mathrm{J}}$, is given by,

$$
d_{\mathrm{J}}\left(m_{1}, m_{2}\right)=\sqrt{\frac{1}{2}\left(\overrightarrow{\mathbf{m}}_{1}-\overrightarrow{\mathbf{m}}_{2}\right)^{\mathrm{T}} \mathbf{J a c}\left(\overrightarrow{\mathbf{m}}_{1}-\overrightarrow{\mathbf{m}}_{2}\right)},
$$

where Jac is a matrix whose elements are Jaccard indices for any pair of subsets of $\Theta$

$$
\operatorname{Jac}\left(A_{i}, A_{j}\right)=\frac{\left|A_{i} \cap A_{j}\right|}{\left|A_{i} \cup A_{j}\right|}, \text { for } A_{i}, A_{j} \in 2^{\Theta} \backslash \emptyset, i, j=1,2, \ldots, 2^{n}-1,
$$

where $|A|$ is the cardinality of $A$. Bouchard et al. (2008) gave a proof for the positive definiteness of the Jaccard index matrix that guarantees that Jousselme's distance is a full metric. The proof is based on the decomposition of the matrix into an infinite sum of positive semidefinite matrices. In fact, Jousselme's distance is an $L_{2}$ Euclidean distance with weighting matrix Jac.

However, when the frame of discernment $\Theta$ is orderable sets, the Jaccard index which uses the cardinality of unions and intersections between focal elements is not suitable for judging similarity. Sunberg et al. (2013) proposed a Hausdorff-based measure to account for the distance between focal elements. The distance maintains the quadratic form structure of Jousselme but replaces the similarity function with,

$$
d_{\text {Haus }}\left(m_{1}, m_{2}\right)=\sqrt{\frac{1}{2}\left(\overrightarrow{\mathbf{m}}_{1}-\overrightarrow{\mathbf{m}}_{2}\right)^{\mathrm{T}} \mathbf{S}_{\text {Haus }}\left(\overrightarrow{\mathbf{m}}_{1}-\overrightarrow{\mathbf{m}}_{2}\right)},
$$

where $\mathbf{S}_{\text {Haus }}$ is a similarity matrix. Each corresponding element is, 


$$
S_{\text {Haus }}=\frac{1}{1+K H\left(A_{i}, A_{j}\right)},
$$

where $H\left(A_{i}, A_{j}\right)$ is the Hausdorff distance between focal elements $A_{i}$ and $A_{j} . K>0$ is a user-defined tuning parameter that adjusts metric responses with respect to the orderable space discretization. In this paper, $K$ is set to 1 . The Hausdorff distance between focal elements may be defined as,

$$
H\left(A_{i}, A_{j}\right)=\max \left\{\left|\min \left(A_{i}\right)-\min \left(A_{j}\right)\right|,\left|\max \left(A_{i}\right)-\max \left(A_{j}\right)\right|\right\},
$$

Because uses the Hausdorff distance, the metric does not reach a saturated value when the two BBAs have no overlap. Moreover, it is a metric distance.

Mo et al. (2016) proposed a generalized evidence distance that combines Jousselme's distance and Sunberg's distance,

$$
d_{\mathrm{G}}\left(m_{1}, m_{2}\right)=\sqrt{\frac{1}{2}\left(\overrightarrow{\mathbf{m}}_{1}-\overrightarrow{\mathbf{m}}_{2}\right)^{\mathrm{T}} \mathbf{D}\left(\overrightarrow{\mathbf{m}}_{1}-\overrightarrow{\mathbf{m}}_{2}\right)},
$$

where $\mathbf{D}=\alpha \mathbf{J a c}+\beta \mathbf{S}_{\text {Haus }}$. The parameters $\alpha$ and $\beta$ are user-defined weighted normalized coefficients, $\alpha, \beta \in[0,1]$, $\alpha+\beta=1$. When BBAs are un-orderable sets, $\alpha$ should be given a bigger weight than $\beta$. When BBAs are orderable sets, the parameter $\beta$ should be given a bigger weight than $\alpha$. For simplicity, both $\alpha$ and $\beta$ are set to be 0.5 . However, the metric properties are not provided.

The indirect distance is computed in a new representation space $F \times F$. The space $F$ is generated by some new vectors that are transformed from BBAs, such as pignistic transforms and belief interval transforms.

Tessem's distance is also called the betting commitment distance or the pignistic probability distance. It is computed by,

$$
d_{\mathrm{T}}\left(m_{1}, m_{2}\right)=\max _{A \subseteq \Theta}\left\{\left|\operatorname{Bet} P_{1}(A)-\operatorname{BetP}_{2}(A)\right|\right\},
$$

where $B e t P_{1}$ and $B e t P_{2}$ are the pignistic probabilities of $m_{1}$ and $m_{2}$, respectively, according to (4). Tessem's distance belongs to the $L_{\infty}$ family of Chebyshev distance and it is actually not a strict distance metric.

Han et al. (2014) proposed two distances based on the belief intervals $[\operatorname{Bel}(A), \operatorname{Pl}(A)]$, here we only make mention of the Euclidean-family belief interval-based distance denoted by $d_{\mathrm{BI}}$. For a BBA, the belief intervals of different focal elements are first calculated, and these can be considered as interval numbers. Given two interval numbers $\left[a_{1}, b_{1}\right]$ and $\left[a_{2}, b_{2}\right]$, a strict distance (Wassersteinbased distance) (Verde \& Irpino 2008) is defined as,

$$
d^{I}\left(\left[a_{1}, b_{1}\right],\left[a_{2}, b_{2}\right]\right)=\sqrt{\left(\frac{a_{1}+b_{1}}{2}-\frac{a_{2}+b_{2}}{2}\right)^{2}+\frac{1}{3}\left(\frac{b_{1}-a_{1}}{2}-\frac{b_{2}-a_{2}}{2}\right)^{2}} .
$$

Therefore, the distance between belief intervals $B I_{1}\left(A_{i}\right)$ (calculated from $m_{1}$ ) and $B I_{2}\left(A_{i}\right)$ (calculated from $m_{2}$ ) can be measured according to. Thus $d_{\mathrm{BI}}$ can be defined as

$$
d_{\mathrm{BI}}\left(m_{1}, m_{2}\right)=\sqrt{N_{c} \sum_{i=1}^{2^{n}-1}\left[d^{I}\left(B I_{1}\left(A_{i}\right), B I_{2}\left(A_{i}\right)\right)\right]^{2}}=\sqrt{N_{c} \cdot \mathbf{d}_{\mathbf{I}} \cdot \mathbf{d}_{\mathbf{I}}^{\mathrm{T}}},
$$

where $N_{c}=1 / 2^{\mathrm{n}-1}$ is the normalization factor, $i=1,2, \ldots$, $2^{n}-1$, and the superscript $\mathrm{T}$ denotes the transpose. $\mathrm{d}_{\mathrm{I}}$ is a $\left(1 \times 2^{n}-1\right)$-dimensional row vector is given by,

$$
\mathbf{d}_{\mathbf{I}}=\left[d^{I}\left(B I_{1}\left(A_{1}\right), B I_{2}\left(A_{1}\right)\right), \cdots, d^{I}\left(B I_{1}\left(A_{2^{n}-1}\right), B I_{2}\left(A_{2^{n-1}}\right)\right)\right] .
$$

Han et al. (2014) also proved that the belief intervalbased distance is a strict metric distance.

The conflict coefficient defined by Dempster in (5) is probably the first quantification of the interaction between two belief functions. Hereafter denoted by $d_{\mathrm{C}}$ is redefine as,

$$
d_{\mathrm{C}}\left(m_{1}, m_{2}\right)=\sum_{A_{i} \otimes A_{j}=\varnothing} m_{1}\left(A_{i}\right) m_{2}\left(A_{j}\right)
$$

However, in some cases it cannot truly reflect the degree of dissimilarity between two BBAs (Liu 2006). Furthermore, $d_{\mathrm{C}}$ is not a metric distance.

For a thorough survey of evidential distances and their classification and properties, see Jousselme and Maupin (2012).

\section{THE PROPOSED DISTANCE OF INTERVAL-VALUED BELIEF STRUCTURE AND ITS PROPERTIES}

We now present the interval distance between two IBSs based on the Hausdorff distance and Jaccard index.

\section{A DISTANCE OF INTERVAL-VALUED BELIEF STRUCTURE}

Definition 8 Given a frame of discernment $\Theta$ with $n$ elements and its related interval-valued belief structures space $\mathrm{S}$, a real function $d: \mathrm{IBS} \times \mathrm{IBS} \rightarrow \mathrm{R}^{+}$is called the metric distance between two interval mass functions $m_{1}$ and $m_{2}$ defined on $\Theta$ if $d$ satisfies the following properties:

(d1) Nonnegativity: $d\left(m_{1}, m_{2}\right) \geq 0$; (d2) Nondegeneracy: $d\left(m_{1}, m_{2}\right)=0 \square \quad m_{1}=m_{2} ;(\mathrm{d} 3)$ Symmetry: $d\left(m_{1}, m_{2}\right)=d$ $\left(m_{2}, m_{1}\right)$; and (d4) Triangle inequality: $d\left(m_{1}, m_{2}\right)+d\left(m_{1}\right.$, $\left.m_{3}\right) \geq d\left(m_{2}, m_{3}\right), \forall m_{3}$ of IBS.

Properties (d1) and (d2) together define positive definiteness.

We then propose to look for a distance measure between two IBSs $m_{1}$ and $m_{2}$ in the form

$$
d\left(m_{1}, m_{2}\right)=\sqrt{\left(\overrightarrow{\mathbf{m}}_{1}-\overrightarrow{\mathbf{m}}_{2}\right)^{\mathrm{T}} \mathbf{S}\left(\overrightarrow{\mathbf{m}}_{1}-\overrightarrow{\mathbf{m}}_{2}\right)}
$$


where $\left(\overrightarrow{\mathbf{m}}_{1}-\overrightarrow{\mathbf{m}}_{2}\right)$ is the distance measure between the intervals of $A_{i}$ for $m_{1}$ and $m_{2} . \mathbf{S}$ is the similarity measure between the focal elements.

For any two subsets $U$ and $W$ of a Babach space $Z$ the Hausdorff metric is simplified to de Carvalho and Pimentel (2012),

$$
d_{\mathrm{H}}(U, W)=\max \left\{\sup _{u \in U} \inf _{w \in W}|u-w|, \operatorname{supinf}_{w \in W}|u-w|\right\} .
$$

If $Z=\mathrm{R}, U=\left[u_{1}, u_{2}\right]$, and $W=\left[w_{1}, w_{2}\right]$ are intervals, using the $L_{1}$ norm (city block distance), the Hausdorff distance $d_{\mathrm{H}}$ between $U$ and $W$ is

$$
d_{\mathrm{H}}(U, W)=\max \left(\left|u_{1}-w_{1}\right|,\left|u_{2}-w_{2}\right|\right)
$$

The matrix $\mathbf{S}$ must be defined to describe the 'similarity' between the subsets of $\Theta$. Jaccard index or Jaccard similarity coefficient defined in (11) was introduced by the botanist Paul Jaccard in 1901, and is now a classical and commonly used measure of similarity between sets in many applications. In this paper we also use the Jaccard index despite its ignorance of the frame of discernment $\Theta$.

Definition 9 Let $m_{1}$ and $m_{2}$ be two IBSs defined on the same FOD $\Theta$, containing $n$ mutually exclusive and exhaustive hypotheses. The distance between $m_{1}$ and $m_{2}$ is defined by,

$$
d_{\mathrm{IBS}}\left(m_{1}, m_{2}\right)=\sqrt{N_{\mathrm{f}} \cdot \mathbf{d}_{\mathbf{H}}^{\mathrm{T}} \cdot \mathbf{J a c} \cdot \mathbf{d}_{\mathbf{H}}}
$$

Here $N_{\mathrm{f}}$ is the normalization factor.

Jac is a $\left(2^{n}-1\right) \times\left(2^{n}-1\right)$ matrix whose elements are Jaccard indexes for all pairs of subsets $A_{i}$ of $\Theta$ with $n$ elements $(n=|\Theta|)$, not including the empty set. The rows and columns of Jac are indexed by the elements $A_{i}$ of $2^{\Theta} \varnothing \varnothing$ and $\mathbf{J a c}\left(A_{i}, A_{j}\right)$ denotes the element of row $A_{i}$ and column $A_{j}$ of Jac in accordance with (11).

$\mathbf{d}_{\mathbf{H}}$ is a column vector of $2^{n}-1$ dimensions, indexed by the sets in $2^{\Theta} \varnothing \varnothing$ and $\mathbf{d}_{\mathrm{H}}^{\mathrm{T}}$ denotes the transpose vector of $\mathbf{d}_{\mathbf{H}}$. The vector $\mathbf{d}_{\mathbf{H}}$ is defined by

$$
\mathbf{d}_{\mathbf{H}}\left(m_{1}, m_{2}\right)=\left[d_{\mathrm{H}}\left(m_{1}\left(A_{1}\right), m_{2}\left(A_{1}\right)\right), \ldots, d_{\mathrm{H}}\left(m_{1}\left(A_{2^{n}-1}\right), m_{2}\left(A_{2^{n}-1}\right)\right)\right]^{\mathrm{T}} .
$$

Every element of $\mathbf{d}_{\mathbf{H}}$ is a Hausdorff distance between two interval-valued BBAs according to (23), and the $i$ th element is

$$
d_{i}=d_{\mathrm{H}}\left(m_{1}\left(A_{i}\right), m_{2}\left(A_{i}\right)\right), \text { for } i=1,2, \ldots, 2^{n}-1
$$

where $A_{i}$ is all subsets of $\Theta$ (excluding $\left.\varnothing\right)$.

\section{PROPERTIES}

The proposed distance measure between two IBSs has the following properties, for which we show the proofs.

Property 1. The normalizatio n factor $N_{\mathrm{f}}=\frac{n}{2(2 n-1)}$.

We first recall some useful theorems for the proof.

Theorem 1 Given that $\mathbf{A}$ is $n \times n$ real symmetric positive definite, for any $n \times 1$ column vector $\mathbf{x}$, there exits the quadratic form $\mathbf{x}^{\mathbf{T}} \mathbf{A} \mathbf{x}=\sum_{i=1}^{n} \sum_{j=1}^{n} a_{i j} x_{i} x_{j} \geq 0$. If and only if for $\mathbf{x}=0, \mathbf{x}^{\mathbf{T}} \mathbf{A} \mathbf{x}=0$.

Early in 1986, Gower (1971) proved that the Jaccard index matrix $\mathbf{J a c}$ is a positive semidefinite similarity matrix, and Bouchard et al. recently provided a proof for the positive definiteness. Here, we provide the conclusion as the following theorem.

Theorem 2 (Positive definiteness of Jac). The Jaccard index matrix formed by $N$ arbitrary subsets of $\Theta$ a frame of reference of size $n$, is positive definite.

Proof of the normalization factor Suppose that $\Theta=\left\{\theta_{1}\right.$, $\left.\theta_{2}, \ldots, \theta_{\mathrm{n}}\right\}, m_{1}$ and $m_{2}$ are two IBSs, and the Hausdorff distance between two elements $A_{i}$ is $\mathbf{d}_{\mathrm{H}}=\left[\begin{array}{lll}d_{1} & \mathrm{~K} & d_{2^{\mathrm{n}}-1}\end{array}\right]^{\mathrm{T}}$, according to (25) and (26).

Obviously, Jac is a real symmetric and positive definite matrix. By Theorem 1 and Theorem 2, Jac and $\boldsymbol{d}_{\mathrm{H}}$ can be translated into the quadratic form,

$$
\begin{aligned}
& d=\mathbf{d}_{\mathbf{H}}^{\mathrm{T}} \cdot \mathbf{J a c} \cdot \mathbf{d}_{\mathbf{H}}=\sum_{i=1}^{2^{n}-12^{2^{n}-1}} \sum_{j=1} d_{i} d_{j} \frac{\left|A_{i} \cap A_{j}\right|}{\left|A_{i} \cup A_{j}\right|}=\sum_{i=1}^{2^{n}-1} d_{i}^{2}+2 \sum_{i=1}^{2^{n}-12^{2^{n}-1}} \sum_{j=1}^{\substack{j>1 \\
j>i}} d_{i} d_{j} \frac{\left|A_{i} \cap A_{j}\right|}{\left|A_{i} \cup A_{j}\right|} . \\
& =d_{1}^{2}+\cdots+d_{2^{n}-1}^{2}+\cdots+\frac{2(n-1)}{n} \underbrace{\left(d_{2^{n}-n} d_{2^{n}-1}+\cdots+d_{2^{n}-2} d_{2^{n}-1}\right)}_{n}
\end{aligned}
$$

Hence, can be rewritten as,

$$
d_{\mathrm{IBS}}\left(m_{1}, m_{2}\right)=\sqrt{N_{\mathrm{f}} \cdot d}=\sqrt{N_{\mathrm{f}}\left(\sum_{i=1}^{2^{n}-1} d_{i}^{2}+2 \sum_{i=1}^{2^{n}-12^{2^{n}-1}} \sum_{\substack{j>i \\ j>i}} d_{j} \frac{\left|A_{i} \cap A_{j}\right|}{\left|A_{i} \cup A_{j}\right|}\right)} .
$$

For the sake of the validity and normalization of the interval-valued belief function, the maximum of distance value is reached when $d_{2^{n}-1}=1$, only one of the distances $d_{2^{n}-1}, d_{2^{n}-(\mathrm{n}-1)}, \ldots, d_{2^{n}-2}$ equals 1 , and the others are 0 . Therefore, the maximum distance is $d=1+1+\frac{2(n-1)}{n}=\frac{2(2 n-1)}{n}$, and the normalization factor is $N_{\mathrm{f}}=\frac{n}{2(2 n-1)}$. 
For example, when $n=3$, then $\Theta=\left\{\theta_{1}, \theta_{2}, \theta_{3}\right\}$ and

$$
\begin{aligned}
& \left\{\theta_{1}\right\}\left\{\theta_{2}\right\}\left\{\theta_{3}\right\}\left\{\theta_{1} \theta_{2}\right\}\left\{\theta_{1} \theta_{3}\right\}\left\{\theta_{2} \theta_{3}\right\}\left\{\theta_{1} \theta_{2} \theta_{3}\right\} \\
& \begin{aligned}
\mathbf{J a c}^{(3)}= & \left\{\theta_{3}\right\} \\
& \left\{\theta_{\theta_{1}}\right\} \quad\left[\begin{array}{ccccccc}
1 & 0 & 0 & 1 / 2 & 1 / 2 & 0 & 1 / 3 \\
0 & 1 & 0 & 1 / 2 & 0 & 1 / 2 & 1 / 3 \\
0 & 0 & 1 & 0 & 1 / 2 & 1 / 2 & 1 / 3 \\
1 / 2 & 1 / 2 & 0 & 1 & 1 / 3 & 1 / 3 & 2 / 3 \\
& \left\{\theta_{1} \theta_{3}\right\} \\
& \left\{\theta_{2} \theta_{3}\right\} \\
& \left\{\theta_{1} \theta_{2} \theta_{3}\right\} \\
1 / 2 & 0 & 1 / 2 & 1 / 3 & 1 & 1 / 3 & 2 / 3 \\
0 & 1 / 2 & 1 / 2 & 1 / 3 & 1 / 3 & 1 & 2 / 3 \\
1 / 3 & 1 / 3 & 1 / 3 & 2 / 3 & 2 / 3 & 2 / 3 & 1
\end{array}\right]
\end{aligned}
\end{aligned}
$$

Let

$$
\begin{aligned}
d & =\mathbf{d}_{\mathbf{H}}^{\mathrm{T}} \cdot \mathbf{J a c}^{(3)} \cdot \mathbf{d}_{\mathbf{H}}=\left(d_{1}^{2}+d_{2}^{2}+d_{3}^{2}+d_{4}^{2}+d_{5}^{2}+d_{6}^{2}+d_{7}^{2}\right) \\
& +\left(d_{1} d_{4}+d_{1} d_{5}+d_{2} d_{4}+d_{2} d_{6}+d_{3} d_{5}+d_{3} d_{6}\right) \\
& +\frac{2}{3}\left(d_{1} d_{7}+d_{2} d_{7}+d_{3} d_{7}+d_{4} d_{5}+d_{4} d_{6}+d_{5} d_{6}\right) \\
& +\frac{4}{3}\left(d_{4} d_{7}+d_{5} d_{7}+d_{6} d_{7}\right)
\end{aligned} .
$$

The maximum distance is reached when $d_{7}=1$ and $\left(d_{4}=1\right.$ or $d_{5}=1$ or $\left.d_{6}=1\right)$, and the others are 0 , therefore, the maximum distance is $d=3 / 10$ and the normalization factor is $N_{\mathrm{f}}=1 / d=10 / 3$.

Property 2 The distance $d_{\mathrm{IBS}}$ is a metric distance.

Proof: Nonnegativity. The Hausdorff distance is in the form of an absolute value, and the Jaccard index matrix is positive definite, therefore, the distance obviously $d_{\mathrm{IBS}}$ $\left(m_{1}, m_{2}\right) \geq 0$.

Nondegeneracy. Given two interval BBAs with mass distributions $\vec{m}_{1}=\vec{m}_{2}$, the vector $\vec{m}_{1}-\vec{m}_{2}=0$, and thus $\mathrm{d}_{\mathrm{IBS}}\left(m_{1}, m_{2}\right)=0$. Conversely, suppose $\mathrm{d}_{\mathrm{IBS}}\left(m_{1}, m_{2}\right)=0$. Since Jac is positive definite and is not a null matrix, it must be true that $\vec{m}_{1}-\vec{m}_{2}=0$, i.e., $\vec{m}_{1}=\vec{m}_{2}$.

Symmetry. Because the Hausdorff distance is symmetric, we can obtain $\mathbf{d}_{\mathbf{H}}\left(m_{1}, m_{2}\right)=\mathbf{d}_{\mathbf{H}}\left(m_{2}, m_{1}\right)$, and then $\mathrm{d}_{\mathrm{IBS}}\left(m_{1}, m_{2}\right)=\mathrm{d}_{\mathrm{IBS}}\left(m_{2}, m_{1}\right)$.

Triangle inequality. Suppose that $m_{1}, m_{2}$ and $m_{3}$ are three IBSs defined on the same FOD $\Theta$ with size of $n$. Since the Hausdorff distance $d_{\mathrm{H}}$ defined in is a metric distance, the triangle inequality is naturally satisfied. That means for each $A_{i}\left(i=1, \ldots, 2^{n}-1\right)$, there exists,

$$
\begin{aligned}
& d_{\mathrm{H}}\left(m_{1}\left(A_{i}\right), m_{2}\left(A_{i}\right)\right)+d_{\mathrm{H}}\left(m_{1}\left(A_{i}\right),\right. \\
& \left.m_{3}\left(A_{i}\right)\right) \geq d_{\mathrm{H}}\left(m_{2}\left(A_{i}\right), m_{3}\left(A_{i}\right)\right) .
\end{aligned}
$$

Denote that $x_{i}=d_{\mathrm{H}}\left(m_{1}\left(A_{i}\right), m_{2}\left(A_{i}\right)\right), y_{i}=d_{\mathrm{H}}\left(m_{1}\left(A_{i}\right)\right.$, $m_{3}\left(A_{i}\right)$, and $z_{i}=d_{\mathrm{H}}\left(m_{2}\left(A_{i}\right), m_{3}\left(A_{i}\right)\right)$, therefore,

$$
x_{i}+y_{i} \geq z_{i} \Rightarrow\left(x_{i}+y_{i}\right)^{2} \geq z_{i}^{2} \Rightarrow \sum_{i=1}^{2^{n}-1}\left(x_{i}+y_{i}\right)^{2} \geq \sum_{i=1}^{2^{n}-1} z_{i}^{2} .
$$

According to the Mikowski inequality,

$$
\sqrt{\sum_{i=1}^{2^{n}-1} x_{i}^{2}}+\sqrt{\sum_{i=1}^{2^{n}-1} y_{i}^{2}} \geq \sqrt{\sum_{i=1}^{2^{n}-1}\left(x_{i}+y_{i}\right)^{2}}
$$

there exists $\sqrt{\sum_{i=1}^{2^{n}-1} x_{i}^{2}}+\sqrt{\sum_{i=1}^{2^{n}-1} y_{i}^{2}} \geq \sqrt{\sum_{i=1}^{2^{n}-1} z_{i}^{2}}$.

Square both sides of inequality to obtain

$$
\sum_{i=1}^{2^{n}-1} x_{i}^{2}+\sum_{i=1}^{2^{n}-1} y_{i}^{2}+2 \sqrt{\sum_{i=1}^{2^{n}-1} x_{i}^{2}} \sqrt{\sum_{i=1}^{2^{n}-1} y_{i}^{2}} \geq \sum_{i=1}^{2^{n}-1} z_{i}^{2}
$$

Then, add some items on both sides of the inequality (33). Comparing this with the left side of (30), we have

$$
\begin{aligned}
& \sum_{i=1}^{2^{n}-1} x_{i}^{2}+2 \sum_{i=1}^{2^{n}-1} \sum_{\substack{j=1 \\
j>i}}^{2^{n}-1} x_{i} x_{j} \frac{\left|A_{i} \cap A_{j}\right|}{\left|A_{i} \cup A_{j}\right|}+\sum_{i=1}^{2^{n}-1} y_{i}^{2}+2 \sum_{i=1}^{2^{n}-12^{n}-1} \sum_{\substack{j=1 \\
j>i}} y_{i} y_{j} \frac{\left|A_{i} \cap A_{j}\right|}{\left|A_{i} \cup A_{j}\right|}
\end{aligned}
$$

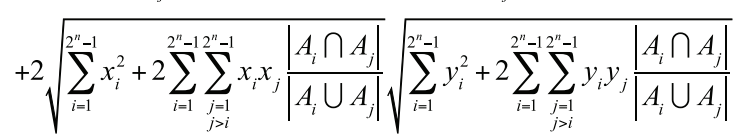

$$
\begin{aligned}
& \geq \sum_{i=1}^{2^{n}-1} z_{i}^{2}+2 \sum_{i=1}^{2^{n}-1} \sum_{\substack{j=1 \\
j>i}}^{2^{n}-1} x_{i} x_{j} \frac{\left|A_{i} \cap A_{j}\right|}{\left|A_{i} \cup A_{j}\right|}+2 \sum_{i=1}^{2^{n}-12^{2^{n}-1}} \sum_{\substack{j=1 \\
j>i}} y_{i} y_{j} \frac{\left|A_{i} \cap A_{j}\right|}{\left|A_{i} \cup A_{j}\right|} \\
& \geq \sum_{i=1}^{2^{n}-1} z_{i}^{2}+2 \sum_{i=1}^{2^{n}-1} \sum_{\substack{2_{j} \\
j>i}}^{2^{n}-1} z_{i} z_{j} \frac{\left|A_{i} \cap A_{j}\right|}{\left|A_{i} \cup A_{j}\right|}
\end{aligned}
$$

Hence,

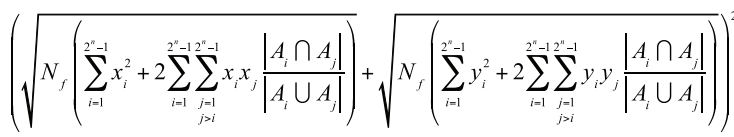

$$
\begin{aligned}
& \geq\left(\sqrt{N_{f}\left(\sum_{i=1}^{2^{n}-1} z_{i}^{2}+2 \sum_{\substack{i=1 \\
2^{n}-12^{2 n-1}}}^{j=1} z_{i j} z_{j} \frac{\left|A_{i} \cap A_{j}\right|}{\left|A_{i} \cup A_{j}\right|}\right)}\right)^{2}
\end{aligned}
$$

Then we obtain

$$
d_{\mathrm{IBS}}\left(m_{1}, m_{2}\right)+d_{\mathrm{IBS}}\left(m_{1}, m_{3}\right) \geq d_{\mathrm{IBS}}\left(m_{2}, m_{3}\right)
$$

Therefore, the property of triangle inequality of $d_{\mathrm{IBS}}$ is satisfied.

Through the mentioned analysis, it can be proved that conditions (d1) to (d4) are satisfied, i.e., the distance $d_{\mathrm{IBS}}$ is a metric distance.

\section{NUMERICAL EXAMPLES}

EXAMPLES FOR THE CASE OF CRISP BELIEF STRUCTURES

Example 1 This example was proposed in Han et al. (2011) and reused in Han et al. (2014). In this example, $m_{1}, m_{2}, \ldots$, 
$m_{7}$ are seven crisp belief structures defined on the same FOD $\Theta=\left\{\theta_{1}, \theta_{2}, \theta_{3}\right\}$, as shown in Table 1 .

The referenced BBA $m_{1}$ has a relatively large mass assignment value for the focal element $\left\{\theta_{2}\right\}$. Intuitively, for $m_{i}(i=2, \ldots, 7)$, the larger the mass assignment value of $\left\{\theta_{2}\right\}$, the smaller the relative distance value. Furthermore, the minimum distance occurs at $i=3$, because $m_{3}$ has the maximum similarity to $m_{1}$. Seven different distances, $d_{\mathrm{J}}, d_{\mathrm{T}}, d_{\mathrm{C}}, d_{\mathrm{BI}}, d_{\text {Haus }}, d_{\mathrm{G}}$ and the proposed distance $d_{\mathrm{IBS}}$ in this paper, are employed. As shown in Figure 1, most of the change trends of the seven curves obtained by these distances are identical except for $d_{\text {Haus }}$. The result demonstrates that the proposed distance is effective for crisp belief structures.

Example 2 This example was proposed in Han et al. (2011) and reused in Han et al. (2014). Let $\Theta=\left\{\theta_{1}, \theta_{2}, \ldots\right.$, $\left.\theta_{n}\right\}$ be a fame of discernment. Three BBAs are defined as follows:

$$
\begin{aligned}
& m_{1}\left(\theta_{1}\right)=\mathrm{m}_{1}\left(\theta_{2}\right)=\ldots=\mathrm{m}_{1}\left(\theta_{n}\right)=1 / n \\
& m_{2}(\Theta)=1 ; m_{3}\left(\theta_{\mathrm{k}}\right)=1, \text { for some } \mathrm{k} \in\{1,2, \ldots, n\}
\end{aligned}
$$

For a given number $n$, it is clear that $m_{1}$ is a Bayesian BBA, $m_{2}$ is a vacuous BBA and $m_{3}$ is a categorical BBA. The results of this experiment are displayed in Figure 2.

It can be noted that, $d_{\mathrm{J}}\left(m_{1}, m_{2}\right)$ and $d_{\mathrm{J}}\left(m_{1}, m_{3}\right)$ are superimposed for Jousselme distance $d_{\mathrm{J}}$. This means that the Bayesian BBA $m_{1}$ is equidistant to the vacuous BBA $m_{2}$ and the categorical BBA $m_{3}$, because. It can also be seen that $d_{\mathrm{T}}\left(m_{1}, m_{2}\right)=0$ because $m_{1}$ and $m_{2}$ have the same pignistic probabilities instead of BBAs. The conflict coefficient cannot be used as the distance metric since $d_{\mathrm{C}}\left(m_{1}, m_{2}\right)=d_{\mathrm{C}}\left(m_{2}, m_{3}\right)=0$. These examples illustrate that $d_{\mathrm{J}}, d_{\mathrm{T}}$ and $d_{\mathrm{C}}$ are poor at discriminating the difference of the three BBAs. By contrast, the curves of $d_{\mathrm{BI}}, d_{\text {Haus }}, d_{\mathrm{G}}$ and $d_{\mathrm{IBS}}$ are not superimposed. For a fixed number $n, m_{1}$ and $m_{3}$ are probability distributions which insist one focal element, as well as $m_{2}$ is ambiguous. Therefore, there is the reason to believe that $m_{1}$ is closer to $m_{3}$ than to $m_{2}$. However, $\mathrm{d}_{\mathrm{BI}}$ accounts for the fact that $d_{\mathrm{BI}}\left(m_{1}, m_{3}\right)$ is bigger than $d_{\mathrm{BI}}\left(m_{1}, m_{2}\right)$, which is unreasonable. It is difficult how to select the tuning parameter $K$ and $\alpha$ for the distances $d_{\text {Haus }}$ and $d_{\mathrm{G}}$. By comparison, the distance $d_{\mathrm{IBS}}$ show the better performance.

\section{EXAMPLE FOR THE CASE OF INTERVAL-BASED BELIEF STRUCTURES}

Example 3 Let $\Theta=\left\{\theta_{1}, \theta_{2}, \theta_{3}\right\}$ be a frame of discernment. The IVBs are all valid and normalized, and are defined in Table 2.

Intuitively, it can be seen from Table 2 that $m_{1}, m_{2}$ and $m_{3}$ give the biggest interval belief values to support $\theta_{1}, \theta_{2}$ and $\theta_{3}$, respectively. In contrast, $m_{4}$ has the same interval values on $\theta_{1}, \theta_{2}$ and $\theta_{3} . m_{5}$ supports the uncertain situation. The results of this experiment are displayed in Figure 3.

TABLE 1. BBAs of Example 1

\begin{tabular}{cccccccc}
\hline $\begin{array}{c}\text { Focal } \\
\text { element }\end{array}$ & $\theta_{1}$ & $\theta_{2}$ & $\theta_{3}$ & $\theta_{1} \cup \theta_{2}$ & $\theta_{2} \cup \theta_{3}$ & $\theta_{1} \cup \theta_{3}$ & $\theta_{1} \cup \theta_{2} \cup \theta_{3}$ \\
\hline$m_{1}$ & 0.1 & 0.8 & 0.1 & 0 & 0 & 0 & 0 \\
$m_{2}$ & 0.8 & 0 & 0 & 0 & 0 & 0 & 0.2 \\
$m_{3}$ & 0 & 0.8 & 0 & 0 & 0 & 0 & 0.2 \\
$m_{4}$ & 0 & 0 & 0.8 & 0 & 0 & 0 & 0.2 \\
$m_{5}$ & 0 & 0 & 0 & 0.8 & 0 & 0 & 0.2 \\
$m_{6}$ & 0 & 0 & 0 & 0 & 0.8 & 0 & 0.2 \\
$m_{7}$ & 0 & 0 & 0 & 0 & 0 & 0.8 & 0.2 \\
\hline
\end{tabular}

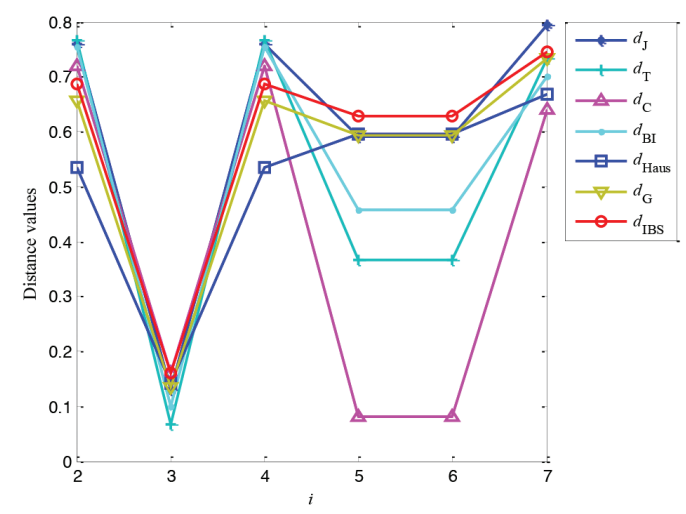

FIGURE 1. Distances between $\mathrm{m}_{1}$ and $\mathrm{m}_{i}, i=2, \ldots, 7$ 
TABLE 2. IVBs of Example 3

\begin{tabular}{ccccc}
\hline $\begin{array}{c}\text { Focal } \\
\text { element }\end{array}$ & $\theta 1$ & $\theta_{2}$ & $\theta_{3}$ & $\theta_{1} \cup \theta_{2} \cup \theta_{3}$ \\
\hline$m_{1}$ & {$[0.75,0.8]$} & {$[0.05,0.1]$} & {$[0.05,0.1]$} & {$[0.1,0.15]$} \\
$m_{2}$ & {$[0.05,0.1]$} & {$[0.75,0.8]$} & {$[0.05,0.1]$} & {$[0.1,0.15]$} \\
$m_{3}$ & {$[0.05,0.1]$} & {$[0.05,0.1]$} & {$[0.75,0.8]$} & {$[0.1,0.15]$} \\
$m_{4}$ & {$[0.3,0.4]$} & {$[0.3,0.4]$} & {$[0.3,0.4]$} & {$[0,0]$} \\
$m_{5}$ & {$[0.1,0.2]$} & {$[0,0]$} & {$[0,0]$} & {$[0.8,0.9]$} \\
\hline
\end{tabular}
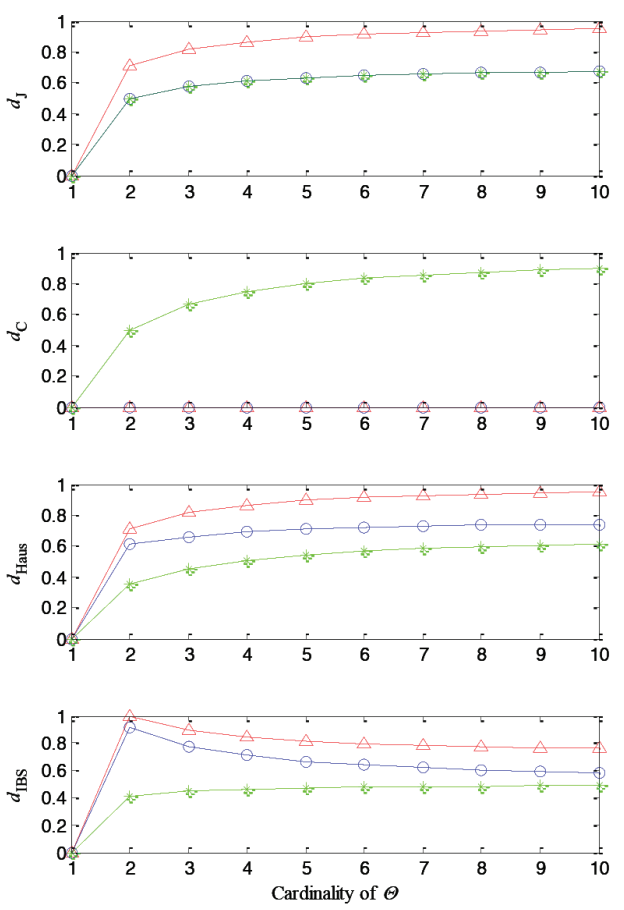

FIGURE 2. Distances between $m_{1}, m_{2}$ and $m_{3}$

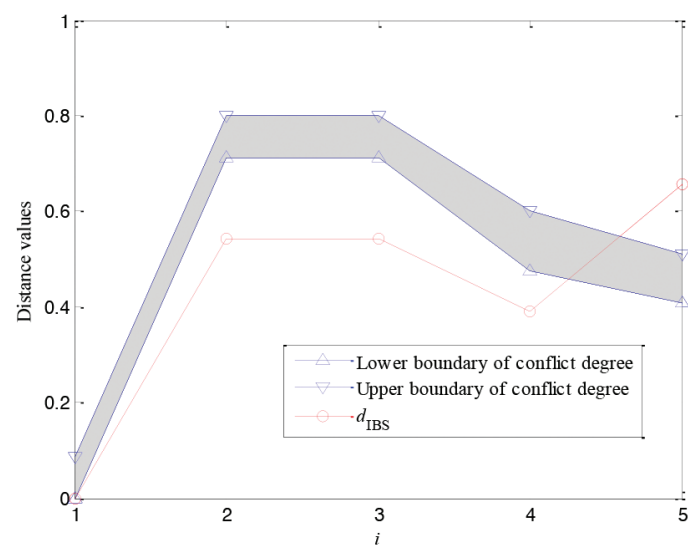

FIGURE 3. Distances between $\mathrm{m}_{1}$ and $\mathrm{m}_{i}, i=1, \ldots, 5$

In Figure 3, the shadow region is the range of conflict degree which can indirectly reflect the distance values between IVBs. When the conflict degree is bigger, it can be considered that the distance value is bigger, and vice versa. From 1 to 4 , the curves are going in the same direction. It is equidistant at $i=2$ and 3 . At $i=4, m_{4}$ has
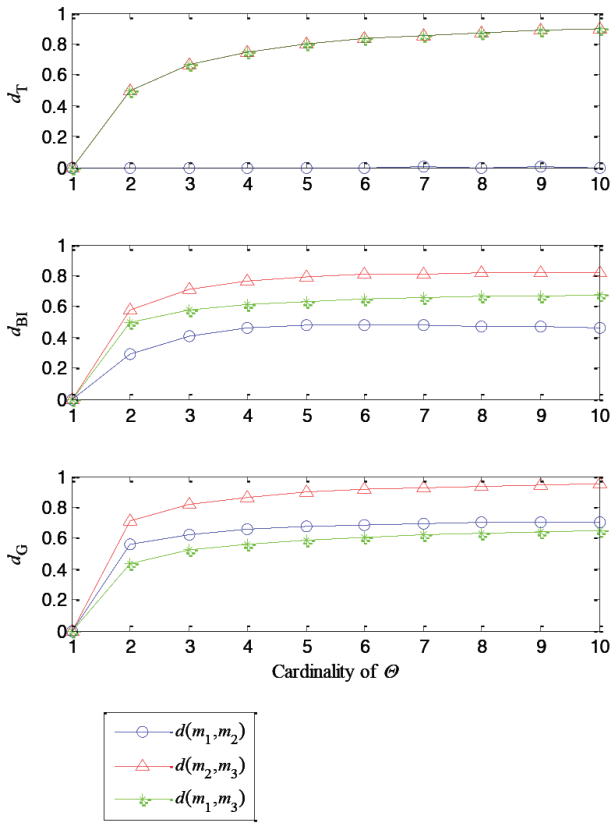

relative larger value on $\theta_{1}$, therefore, the distance becomes closer. Meanwhile, at $i=5$ the conflict degree becomes smaller, which is unreasonable obviously. By contrast, the distance $d_{\mathrm{IBS}}$ also show the better performance.

\section{CONCLUSION}

In this paper, we have investigated the distance measurement problem in interval-valued belief structures. The proposed distance maintains the quadratic form structure using the Jaccard similarity index to compare the focal elements and the Hausdorff distance to measure the distance of interval numbers. Theoretical studies have shown it to be a full metric distance that satisfies the properties of non-negativity, non-degeneracy, symmetry and triangle inequality. Numerical experimental results showed that the proposed distance can be used in both crisp and intervalvalued belief structures. None of the distance measures can be said to be superior to the others in the absolute and the choice of such a measure should always be guided by practical considerations relative to a specific application. Future work will include the following: Further detailing 
the formal properties of the surveyed measures; using real data for experimental comparisons; and using the distance in applications, such as conflict evidence combination, uncertainty measures, and belief function approximation.

\section{ACKNOWLEDGEMENTS}

This work was supported by the Major Science and Technology Program of Shanxi Province, China (Grant no. 20121101004). The authors declare that they have no competing interests.

\section{REFERENCES}

Bauer, M. 1997. Approximation algorithms and decision making in the Dempster-Shafer theory of evidence - An empirical study. International Journal of Approximate Reasoning 17: 217-237.

Bouchard, M., Jousselme, A.L. \& Doré, P.E. 2013. A proof for the positive definiteness of the Jaccard index matrix. International Journal of Approximate Reasoning 54: 615-626.

Carrillo Pedroza, F.R., Soria Aguilar, M.D.J., Sanchez Castillo, M.A., Martinez Luevanos, A. \& Picazo Rodriguez, N.G. 2017. Adsorption of chromium from steel plating wastewater using blast furnace dust. Revista Internacional De Contaminacion Ambiental. 33: 591-603.

Cuzzolin, F. 2011. Lp consonant approximation of belief functions in the mass space. International Symposium on Imprecise Probability Theories and Applications Innsbruck Austria 22: 420-436.

Cuzzolin, F. 2008. A geometric approach to the theory of evidence. IEEE Transactions on Systems Man and Cybernetics Part C - Applications and Reviews 38: 522-534.

de Carvalho, F.D.T. \& Pimentel, J.T. 2012. Partitioning fuzzy clustering algorithms for interval-valued data based on Hausdorff distances. IEEE International Conference On Systems, Man, and Cybernetics (SMC), Seoul, South Korea. pp. 1379-1384.

Dempster, A.P. 1967. Upper and lower probabilities induced by a multi-valued mapping. Annals of Mathematical Statistics 38: 325-339.

Deng, Y., Shi, W.K., Zhu, Z.F. \& Liu, Q. 2004 . Combining belief functions based on distance of evidence. Decision Support Systems 38: 489-493.

Denoeux, T. 1999. Reasoning with imprecise belief structures. International Journal of Approximate Reasoning 20: 79-111.

Denoeux, T. 2000. A neural network classifier based on DempsterShafer theory. IEEE Transactions on Systems Man and Cybernetics - Part A Systems and Humans 30: 131-150.

Diaz, J., Rifqi, M. \& Bouchon-Meunier, B. 2006. A similarity measure between basic belief assignments. Information Fusion: 9th International Conference. pp. 1-6.

Fallatah, M.M., Kavil, Y.N., Ibrahim, A.S.A., Orif, M.I., Shaban, Y.A. \& Farawati, R.A. 2018. Hydrographic parameters and distribution of dissolved $\mathrm{Cu}, \mathrm{Ni}, \mathrm{Zn}$ and nutrients near Jeddah desalination plant. Open Chemistry 16: 246-257.

Fu, C. \& Yang, S.L. 2012. The conjunctive combination of interval-valued belief structures from dependent sources. International Journal of Approximate Reasoning 53: 769-785.

Fu, C. \& Yang, S.L. 2011. Analyzing the applicability of Dempster's rule to the combination of interval-valued belief structures. Expert Systems with Applications 38: 4291-4301.
Giang, P.H. 2015. Decision making under uncertainty comprising complete ignorance and probability. International Journal of Approximate Reasoning 62: 27-45.

Gower, J.C. 1971. A general coefficient of similarity and some of its properties. Biometrics 27: 857-871.

Han, D., Dezert, J. \& Yang, Y. 2014. New distance measures of evidence based on belief intervals. In Belief Functions: Theory and Application. BELIEF 2014. Lecture Notes in Computer Science, edited by Cuzzolin, F. Switzerland: Springer. 8764: 432-441.

Han, D., Dezert, J., Han, C. \& Yang, Y. 2011. New dissimilarity measures in evidence theory. Information Fusion (FUSION), Proceedings of the 14th International Conference. pp. 1-7.

Hariz, S.B., Elouedi,Z.\& Mellouli, K. 2006. Clustering approach using belief function theory. Lecture Notes in Computer Science 4183: 162-171.

Huh, E., Lim, S., Kim, H.G., Ha, S.K., Park, H., Huh, Y. \& Oh, M.S. 2018. Ginger fermented with schizosaccharomyces pombe alleviates memory impairment via protecting hippocampal neuronal cells in amyloid beta(1-42) plaque injected mice. Food and Function 9: 171-178.

Jaccard, P. 1901. Distribution de la Flore Alpine dans le Bassin des Dranses et dans quelques régions voisines. Bulletin De La Societe Vaudoise Des Sciences Naturelles 37: 241-272.

Jiang, W. \& Wang, S. 2017. An uncertainty measure for intervalvalued evidences. Int. J. Comput. Commun. Control 12: 631-644.

Jousselme, A.L. \& Maupin, P. 2012. Distances in evidence theory: Comprehensive survey and generalizations. International Journal of Approximate Reasoning 53: 118-145.

Jousselme, A.L., Grenier, D. \& Bossé, É. 2001. A new distance between two bodies of evidence. Information Fusion 2: 91-101.

Kaushik, N. \& Chatterjee, N. 2018. Automatic relationship extraction from agricultural text for ontology construction. Information Processing in Agriculture 5: 60-73.

Klein, J., Destercke, S. \& Colot, O. 2016. Interpreting evidential distances by connecting them to partial orders: Application to belief function approximation. International Journal of Approximate Reasoning 71: 15-33.

Lee, E.S. \& Zhu, Q. 1992. An interval dempster-shafer approach Computers and Mathematics with Applications 24: 89-95.

Li,Z., Han, C. \& Gu, T. 2018. Economics of biomass gasification: A review of the current status. Energy Sources Part B Economics Planning and Policy 13: 137-140.

Liu, Z., Pan, Q. \& Dezert, J. 2014. A belief classification rule for imprecise data. Applied Intelligence 40: 214-228.

Liu, W.R. 2006. Analyzing the degree of conflict among belief functions. Artificial Intelligence 170: 909-924.

Loudahi, M., Klein, J., Vannobel, J.M. \& Colot, O. 2016. Evidential matrix metrics as distances between meta-data dependent bodies of evidence. IEEE Transactions on Cybernetics 46: 109-122.

Martin, A., Jousselme, A.L. \& Osswald, C. 2008. Conflict measure for the discounting operation on belief functions. International Conference on Information Fusion pp. 1-8.

Mo, H.M., Lu, X. \& Deng, Y. 2016. A generalized evidence distance. Journal of Systems Engineering and Electronics 27: 470-476.

Oyekale, A.S. 2017. Cocoa farmers' safety perception and compliance with precautions in the use of pesticides in centre and western cameroon. Applied Ecology and Environmental Research 15: 205-219. 
Sevastianov, P., Dymova, L. \& Bartosiewicz, P. 2012. A framework for rule-base evidential reasoning in the interval setting applied to diagnosing Type 2 diabetes. Expert Systems with Applications 39: 4190-4200.

Sevastjanov, P., Bartosiewicz, P. \& Tkacz, K. 2010. The normalization of the Dempster's Rule of combination. Artificial Intelligence and Soft Computing, Pt II 6114: 659666.

Shafer, G. 1976. A Mathematical Theory of Evidence. Princeton: Princeton University Press.

Sigren, J.M., Figlus, J., Highfield, W., Feagin, R.A. \& Armitage, A.R. 2018. The effects of coastal dune volume and vegetation on storm-induced property damage: Analysis from hurricane ike. Journal of Coastal Research 34: 164-173.

Skibicki, D., Pejkowski, L. \& Stopel, M. 2017. Finite element analysis of ventilation system fire damper dynamic timehistory. Polish Maritime Research 24: 116-123.

Smets, P. \& Kennes, R. 1994. The transferable belief model. Artificial Intelligence 66: 191-234.

Song, Y., Wang, X., Lei, L. \& Yue, S. 2016. Uncertainty measure for interval-valued belief structures. Measurement 80: 241250.

Song, Y., Wang, X., Lei, L. \& Xue, A. 2014. Combination of interval-valued belief structures based on intuitionistic fuzzy set. Knowledge-Based Systems 67: 61-70.

Sunberg, Z. \& Rogers, J. 2013. A belief function distance metric for orderable sets. Information Fusion 14: 361-373.

Tessem, B. 1993. Approximations for efficient computation in the theory of evidence. Artificial Intelligence 61: 315-329.

Thierry, D. \& Philippe, S. 2007. Classification using belief functions: Relationship between case-based and modelbased approaches. IEEE Transactions on Systems, Man, and Cybernetics, Part B (Cybernetics) 36: 1395-1406.

Verde, R. \& Irpino, A. 2008. A new interval data distance based on the Wasserstein metric. In Data Analysis, Machine Learning and Applications. Studies in Classification, Data Analysis, and Knowledge Organization, edited by Preisach, C., Burkhardt, H., Schmidt-Thieme, L. \& Decker, R. Berlin, Heidelberg: Springer-Verlag. pp. 705-712.

Wahi, N., Bhatia,A.K. \& Bhadauria, S. 2018. Impact of protozoan vahlkampfia sp on the growth of algae Chlorella vulgaris glamtr. Journal of Environmental Biology 39: 109-115.

Wang, Y.M., Yang, J.B., Xu, D.L. \& Chin, K.S. 2007. On the combination and normalization of interval-valued belief structures. Information Sciences 177: 1230-1247.

Wu, Y., Ren, Z. \& Zeng, Z. 2010. Fault diagnosis method based on D-S evidence theory. Prognostics and Health Management Conference. pp. 1-4.
Xu, X.B., Feng, H.S. \& Wen, C.L. 2012. A normalization method of interval-valued belief structures. Information - An International Interdisciplinary Journal 15: 239-248.

Yager, R.R. 2001. Dempster-Shafer belief structures with interval valued focal weights. International Journal of Intelligent Systems 16: 497-512.

Yang, Y. \& Han, D. 2015. A new distance-based total uncertainty measure in the theory of belief functions. Knowledge-Based Systems 94: 114-123.

Yang, Y., Zhong, M., Yao, H., Yu, F., Fu, X. \& Postolache, O. 2018. Internet of things for smart ports: Technologies and challenges. IEEE Instrumentation and Measurement Magazine 21: 34-43.

Yuan, K., Xiao, F., Fei, L., Kang, B. \& Deng, Y. 2016. Modeling sensor reliability in fault diagnosis based on evidence theory. Sensors 16: 113

Zouhal, L.M. \& Denoeux, T. 1998. An evidence-theoretic k-NN rule with parameter optimization. Systems Man and Cybernetics Part C (Applications and Reviews) 28: 263-271.

Junqin Cao \& Xueying Zhang*

College of Information and Computer

Taiyuan University of Technology

Taiyuan, 030024

China

Junqin Cao

School of Electronic Information Engineering

Taiyuan University of Science and Technology

Taiyuan, 030024

China

Jiapeng Feng

Tai Yuan Institute of China Coal Technology and Engineering Group

Taiyuan, 030024

China

*Corresponding author; email: tyzhangxy@163.com

Received: 21 February 2019

Accepted: 23 December 2019 